\title{
Bruxas de hoje: construção identitária do slowbeauty"
}

\author{
Isabela Braga de Moura** \\ Monica Machado***
}

\section{Resumo}

Esta pesquisa propõe-se a compreender a construção da identidade e a relação com o corpo da comunidade de slowbeauty Vivo Naturalmente. Com base nas teorias da antropologia digital de tradição inglesa, do consumo como processo cultural e dos sentidos atribuídos ao corpo, realiza uma etnografia desvelando os significados por trás das práticas da comunidade e traça um retrato da identidade "bruxesca" construída em suas interações presenciais e online. Através da transformação, que se inicia no ritual de passagem, as integrantes vivem uma retomada do corpo negociando valores $e$ significados sociais das mulheres. O estudo identifica ainda uma busca pela essência feminina aparentemente contraditória, mas que revela o poder feminino, e suas dimensões políticas e sociais.

Palavras-chave: Comunidade, Corpo, Identidade, SlowBeauty, Consumo.

\footnotetext{
* Recebido em 27 de maio de 2019, aceito em 10 de agosto de 2020. O presente trabalho foi realizado com apoio da Coordenação de Aperfeiçoamento de Pessoal de Nível Superior - Brasil (CAPES) - Código de Financiamento 001.

${ }^{* *}$ Mestre em Psicossociologia de Comunidades e Ecologia Social, EICOS - Instituto de Psicologia - UFRJ, Rio de Janeiro, RJ, Brasil. bela_braga@outlook.com / https://orcid.org/0000-0001-9149-0954

*** Professora Associada da Escola e Comunicação da UFRJ e do Programa de Pós-Graduação em Psicossociologia de Comunidades e Ecologia Social, EICOS - Instituto de Psicologia - UFRJ, Rio de Janeiro, RJ, Brasil. monica.machado@eco.ufrj.br / https://orcid.org/0000-0002-2558-5426
} 
Contemporary Witches: Identity Construction of Slow Beauty

\begin{abstract}
This study proposes to understand the construction of identity and its relation with the body in the slow beauty community Vivo Naturalmente. Based on theories of digital anthropology from the English tradition, consumption as a cultural process, and meanings attributed to the body, an ethnography is conducted unveiling the meanings behind practices of the community. A portrait is sketched of the identity of "witch" constructed in the community's face-to-face and online interactions. Through a transformation that begins with the ritual of passage, the members experience a retaking of the body, negotiating women's social values and meanings. The study also identifies a pursuit for an apparently contradictory feminine essence, but which reveals female power, and its political and social dimensions.
\end{abstract}

Keywords: Community, Body, Identity, Slow Beauty, Consumption. 


\section{Introdução}

Este estudo investiga a questão da construção identitária e da imagem corporal feminina de uma comunidade de slow beauty a partir do consumo. Os estudos de consumo de cosmético examinaram a construção identitária, especialmente a partir da beleza como commodity e seus produtos (Clark, 2016), das escolhas das práticas de beleza (Stuart; Donaghue, 2012), da formação da subjetividade em espaços como Salão de Beleza (Ossman, 2002) e da beleza como emancipação da mulher moderna (Peiss, 2001), poucos relacionaram corpo, identidade e consumo. O presente estudo avança ainda ao investigar a questão à luz de um fenômeno recente como o slow beauty em um dos maiores mercados de cosméticos do mundo.

Para tanto, foi investigada uma comunidade de consumo consciente com presença também no ambiente digital. A Vivo Naturalmente foi fundada em 2015 por Fernanda Telles e Alcir Blondet após não encontrarem no mercado produtos naturais para cuidar da higiene e da saúde da filha Iasmim. Hoje, Fernanda e Alcir vendem cosméticos e produtos para cuidado de bebês e ministram cursos e oficinas de saboaria, alquimia e aromaterapia. Fernanda busca compartilhar conhecimento sobre um estilo de vida mais saudável e cosmética natural. Ela mantém dois grupos no WhatsApp chamados Vivo Naturalmente e Compras Coletivas com todos os participantes para discussões e contribuições para o movimento. Ainda que estudos etnográficos não partam de hipóteses muito rígidas, iniciamos a investigação a partir das seguintes inquietações: (i) como o movimento slow beauty impacta na identidade de suas integrantes; (ii) como o movimento slow beauty transforma a relação das integrantes com o corpo.

O Brasil é o terceiro maior mercado de cosméticos, respondendo por 9,4\% dos produtos de beleza consumidos no mundo (Euromonitor, 2016). Esse cenário deve-se, em grande parte, ao fenômeno fast beauty. o belo ligado a uma padronização estética na qual a juventude é indispensável (Ishida, 2006). Nesse contexto, os cosméticos devem oferecer efeitos imediatos de manutenção da juventude. Esse consumo imediatista em grande escala ultrapassou a capacidade da Terra de repor os recursos naturais (Rede WWF, 2014). Diante de tal desafio, a atenção a questões de sustentabilidade cresceu. Em oposição ao sistema fast surgiu na década de 1980, na Itália, a tendência slow nas mais diferentes áreas; na alimentar, slow food; na moda, slowfashion; e na beleza, slowbeauty. A busca pelo padrão deu lugar a uma valorização da beleza individual das mulheres ${ }^{1}$. Em lugar da juventude, a beleza de cada idade. Ishida (2006) acredita que o fenômeno da cosmética natural é o próximo estágio social. Dados do Google Trend confirmam a tendência, enquanto o slow food e o slowfashion são mais procurados na plataforma de pesquisa Google, apenas o slow beauty apresentou crescimento nos últimos 2 anos.

Através da Internet, as adeptas ao slow beauty puderam ter acesso à informação instantaneamente. A web não só provocou uma mudança no cenário do consumo feminino, como difundiu o movimento. Sites, blogs e, principalmente, grupos nas redes sociais, as chamadas comunidades virtuais, têm sido utilizadas como plataforma de compartilhamento de conhecimento $e$ construção desse fenômeno. Bookchin (2010) aponta que apenas as ações coletivas e o estabelecimento de uma relação consciente entre cultura e natureza trariam mudanças significativas ao meio ambiente. Nesse contexto, as comunidades virtuais de consumo consciente, enquanto espaços coletivos, possuem grande potencial na adoção de uma nova relação com a natureza e na redução do impacto sobre ela.

A subdisciplina da Antropologia Digital, com forte tradição inglesa, tem particular interesse pelo debate acerca das mediações socioculturais das plataformas digitais e por seus usos sociais, especialmente diante do aumento das experiências cotidianas por meio dessas plataformas (Horst; Miller, 2012). Adotar essa perspectiva é reconhecer o digital como um espaço autêntico de mediação e, como aponta seu princípio dialético, a possibilidade da cultura digital de produzir efeitos negativos e positivos. Isto é, o uso da infraestrutura para controle em regimes de poder ou o surgimento de movimentos de vanguarda, sem espaço nas mídias tradicionais, para construção colaborativa e trocas como o slow beauty.

\footnotetext{
1 A categoria mulheres no plural vem ao encontro dos debates nos estudos de gênero que reconhecem a multiplicidade e a complexidade da identidade social da qual gênero é um dos traços.
} 
Com o intuito de compreender o contexto e os indivíduos em suas relações com a cultura, o estudo aborda a vida cotidiana através de uma etnografia no ambiente presencial e digital. A abordagem da vida cotidiana deve contemplar as diferentes plataformas que compõem a vida diária, se grande parte do tempo é vivido no ambiente online, as pesquisas também devem ser feitas nessa esfera (Miller et al., 2016). A internet é compreendida aqui como um fenômeno incorporado, corporificado e cotidiano (Hine, 2015). A partir dela, as pessoas se conectam, desenvolvem novas identidades $e$ formações sociais. Conforme supracitado, ela desempenha um papel importante na disseminação e construção do movimento no caso do slow beauty, e, portanto, o método adotado contempla a complexidade do fenômeno em suas dimensões da vida diária.

Ao contrário dos estudos que condenam o consumo por compreendê-lo sob a ótica materialista, hedonista e excludente, o presente trabalho foca nas satisfações simbólicas da apropriação coletiva em relações de solidariedade e de distinção. A perspectiva adotada é a de integração. Os bens comunicam e cumprem uma função de mediação das relações socioculturais em arenas de significação. Para além do valor prático, interessa o valor simbólico e os diferentes sentidos que eles evocam. O consumo é compreendido aqui como um processo cultural, no qual o ser humano recebe e envia mensagens (Canclini, 1995; Appadurai, 2009). É a apropriação e o uso de produtos dentro de processos socioculturais que demandam uma racionalidade sociopolítica interativa. A lógica que o rege não é a de satisfação de necessidades, mas de "dar sentido ao fluxo rudimentar dos acontecimentos" (Canclini, 1995:83) e os bens são marcadores de sentido (Barbosa, 2004; Machado 2011).

Portanto, o presente trabalho adota a perspectiva teórica de Canclini (1995), Appadurai (2009), Barbosa (2004), Machado (2011) e Douglas e Isherwood (2013), com especial atenção ao fluxo de trocas marcadas pelos bens e o mapeamento da vida cotidiana através do consumo. Os bens são compreendidos como marcadores e parte do processo de reprodução social. Adota também a perspectiva de Rodrigues (1979; 2014), Reischer e Koo (2004), Douglas (1970) e Mauss (2003), considerando a sensorialidade e os processos corporais como fenômenos sociais capazes de revelar crenças, valores e expectativas, através dos sentidos que são atribuídos ao corpo por uma cultura.

\section{Corpo}

Para compreender a teia de significados e as trocas sociais é necessário considerar o corpo como um aspecto fundamental da cultura (Silva; Covaleski, 2016). Os hábitos e consumo ligados à beleza são construídos socialmente e profundamente marcados pelo contexto. A sensorialidade e os processos corporais também são fenômenos sociais e reveladores de uma cultura, uma vez que estão envolvidos por crenças, valores e expectativas. É através das relações que são atribuídos sentidos ao corpo e suas partes (Rodrigues, 1979; 2014).

Superando os estudos que concebem o corpo como puramente biológico, autores como Turner (1994), Douglas (1970) e Mauss (2003) apontaram questões socioculturais e históricas do fenômeno. A partir do entendimento de uma essência simbólica e dos debates antropológicos entre natureza e cultura, o corpo tornou-se objeto da investigação social (Turner, 1994). Douglas (1970) foi uma das primeiras autoras a discutir os significados simbólicos do corpo. Fazendo uma metáfora com o texto, ele pode ser lido como um símbolo do mundo social, ou seja, há um vocabulário comum que regula os significados sociais inscritos no corpo. Para Mauss (2003), o corpo é moldado pela cultura que determina o que o autor chama de "técnicas do corpo". Através dessas técnicas, o indivíduo é capaz de conhecer a cultura e socializar.

Antes de prosseguirmos com a discussão, é preciso sinalizar uma armadilha linguística quando se trata do corpo. Atualmente, muito se fala que o ser humano "tem" um corpo, dando o sentido de propriedade privada. É evidente que essa concepção está atrelada a uma visão capitalista e traz com ela pressupostos delicados. De um outro lado, temos o ser humano como um corpo que também implica concepções frágeis. Há ainda o "uso" do corpo, especialmente em Mauss (2003). Da mesma forma, a ideia do corpo como ferramenta suscita discussões. Claramente a maneira pela qual fazemos referência ao corpo exprime nossa cosmovisão e pode ser um tanto quanto 
problemática. Portanto, é preciso trazer a reflexão da dificuldade de se referir a ele sem incorporar os inconvenientes de cada concepção.

De maneira semelhante, há um debate sobre a concepção puramente individual do corpo que a tradição ocidental carrega. A ligação aparentemente absoluta e universal de corpo $e$ identidade não é válida para todas as culturas e precisa ser pontuada. Em Fiji, por exemplo, o corpo é muito mais um reflexo da comunidade do que de si e seu cuidado é de responsabilidade de todos (Becker, 1994). O prestígio social do corpo, enquanto coletivo, é visto por aqueles que lhe cercam e não pelo seu próprio. As noções de identidade e coletividade são postas em questão em uma cultura na qual o corpo é propriedade comunitária e não o fundamental do eu.

Partimos do pressuposto de que as ideias, em especial as que envolvem o corpo, não são puramente individuais. Questões históricas e sociais moldam nossos sentidos, que são transformados de acordo com as configurações da época e, portanto, devem ser consideradas em um estudo sobre cultura e comportamento. Se existe hoje um padrão de beleza ligado a mulheres magras e sensuais e homens atléticos e viris ${ }^{2}$ (Silva; Covaleski, 2016), é preciso lembrar que nem sempre foi assim. Rodrigues (2014) aponta mudanças filosóficas e existenciais que influenciaram os valores e associações simbólicas do corpo como veremos posteriormente.

Adotar uma perspectiva antropológica sobre o tema inclui considerar a cultura como um aspecto particular das sociedades humanas. Em oposição ao natural, fazem parte da cultura a tradição social, os comportamentos apreendidos, as normas, hábitos, costumes e tudo o que compõe as regras de determinada sociedade. Judith Butler (2014) argumenta que as normas, implícitas e de difícil percepção, se dão no âmbito das práticas sociais. Elas são reafirmadas "durante e ao longo dos rituais sociais cotidianos da vida corporal" e ainda que se opere fora delas, as normas permanecem como parâmetro de definição (Butler, 2014:262). No que diz respeito ao gênero como norma reguladora, Butler recorre à Foucault para enfatizar suas características disciplinar e de vigilância enquanto forma de poder. É preciso ainda enfatizar que essas são categorias discursivas sócio-históricas e não imutáveis. Nesse sentido, a cultura é como um mapa que guia as práticas cotidianas, representando o território a ser decifrado segundo uma determinada lógica. Esses sistemas de representação classificam, codificam e transformam o mundo estabelecendo fronteiras para as condutas, o que inclui aquelas relativas ao corpo e à beleza.

É preciso, portanto, conceber o corpo dentro de uma lógica comunicacional. Através dele enviamos e recebemos mensagens e nos comunicamos com os outros indivíduos. Exprimimos sentimentos, crenças e valores que são particulares à estrutura social. Enquanto uma mulher americana consegue identificar o estado civil de casada de outra que usa um anel no terceiro dedo da mão esquerda, ela dificilmente identificaria uma indiana com o sári branco como viúva (Reischer; Koo, 2004). Nesse sentido, os usos do corpo demarcam características particulares da cultura na qual está inserido. As classificações, codificações e transformações do sistema de representação funcionam como uma linguagem, que serve para pensar a dinâmica social assim como os bens. Dessa forma, ele se configura também como uma importante peça para o cientista social acessar os fundamentos da sociedade a qual investiga. No entanto, é preciso destacar que, em uma mesma sociedade, os valores e crenças mudam com o passar do tempo.

\section{Beleza, uma questão de gênero}

A partir da compreensão do corpo como parte da estrutura social e revelador da racionalidade de uma cultura, partimos para a discussão da beleza. Conforme abordado anteriormente, nossas ideias e sensibilidades estão intimamente ligadas ao contexto social $e$ histórico em que vivemos. A beleza é, nesse sentido, uma ideia cultural que expressa e carrega valores, crenças e expectativas da conjuntura, ou seja, aquilo que é belo para uma comunidade

\footnotetext{
2 Compreendemos mulheres sensuais e homens viris a partir da noção de gênero enquanto mecanismo de produção de naturalização do masculino e feminino (Butler, 2014). Cabe ressaltar que as leituras identitárias não são fixas, mas, como afirma Bulter (2010:54), "termo em processo, um devir, um construir de que não se pode dizer com acerto que tenha uma origem ou um fim. Como uma prática discursiva contínua, o termo está aberto a intervenções e ressignificações”. Nesse sentido, o padrão se refere à feminilidade atrelada a atração sexual e à masculinidade representada pela força física que os corpos atléticos exaltam.
} 
pode ser o oposto para outra (Reischer; Koo, 2004). Para demonstrar tal particularidade da beleza, Rodrigues (1979) aponta o ideal estético de mulheres da África Central que são submetidas a procedimentos para ficarem mais gordas desde a adolescência, bem diferente da beleza magra ocidental. Já na África do Sul, há povos que retiram os incisivos superiores. Tais exemplos revelam a especificidade da ideia de beleza para cada cultura e como as modificações corporais servem a esse propósito.

Não somente os hábitos de higiene, o enclausuramento dos indivíduos e a criação de uma intimidade que deve ser preservada evidenciam as ações sobre o corpo, "se considerarmos todas as modelações que sofre, constataremos que o corpo é pouco mais que uma massa de modelagem à qual a sociedade imprime formas segundo suas próprias disposições" (Rodrigues, 1979:62). As modelagens e impressões que nele fazemos trazem as marcas da vida social, transformamos nossa fisionomia para nos comunicarmos e exprimirmos os valores de nossa cultura, como exemplifica Rodrigues (1979:62): "arranhando, rasgando, perfurando, queimando a pele - imprimem-se cicatrizes-signos que são formas artísticas ou indicadores rituais de status, como as mutilações do pavilhão auricular, corte ou distensão do lóbulo, etc".

A participação em um grupo social, a reivindicação de uma identidade, a oposição a uma outra subcultura e a mudança de status social são alguns dos motivos para transformações físicas no corpo. No entanto, Reischer e Koo (2004) apontam as mudanças estéticas para atingir a beleza como uma das maiores motivações. Essas modificações também ocorrem na busca pela beleza ou pelo padrão estético definido socialmente, seja ele qual for, e, para isso, acentuamos, escondemos ou reduzimos aspectos de nossa aparência. Muitas vezes o fazemos de forma inconsciente, seguindo um ritual que nos foi passado, por exemplo, a lavagem do cabelo, ou com uma finalidade mítica, como a higiene, evidenciando a importância dos mitos e ritos como informação para o presente estudo. De toda forma, as modificações corporais são um importante aspecto do estudo de uma cultura do slow beauty.

A extensa literatura sobre o corpo das mulheres (Reischer; Koo, 2004; Peiss, 2011; Banner, 1983; Balsamo, 1996; Ossman, 2002, Scanlon, 2000) revela a beleza como um palco de construção de gênero, em especial o feminino. Ainda que autoras como Connell (1995), Bordo (1993) e Faludi (1999) tenham estudado a relação entre beleza e masculinidade, a questão da aparência é, tradicionalmente, uma característica feminina de atração. A historiadora cultural Banner (1983:9, tradução nossa) a identificou como uma "categoria especial da experiência feminina", beleza é quase sinônimo de ser feminina. Nesse contexto, corpo é usado para criar fronteiras, delimitando a atuação de acordo com o gênero. O ideal do corpo feminino está ligado à definição de natureza feminina e do que mulheres podem fazer, ou seja, sua posição social também é influenciada pela construção de gênero. Nesse contexto, a natureza é utilizada para sustentar essa estrutura, ou seja, o discurso biológico e médico naturaliza aspectos culturais do corpo (Reischer; Koo, 2004).

Beauvoir (2014) argumenta que a essência feminina é uma construção cultural e está além das questões biológicas. Para a filósofa, o corpo não basta para definir e limitar mulheres, elas são um vir a ser. Butler (2010:34-35) também desnaturaliza o conceito de essência e aprofunda a questão ao enfatizar a "multiplicidade das interseções culturais, sociais e políticas em que é construído o espectro concreto das "mulheres". Mais além, enfatiza sua noção sócio-histórica que os estilos de vida, os modos de ser e as identidades norteiam. Joan Scott (1995), por sua vez, discute gênero como uma categoria analítica e ressalta sua historicidade. A autora propõe ainda analisar as representações simbólicas e seus contextos, conceitos normativos e como as identidades de gênero são construídas, questionando o "papel tradicional" das mulheres.

Mais ainda, o gênero como categoria analítica possibilita compreender relações complexas de poder que delimitam os papéis baseados na suposta essência ou natureza. As definições normativas de gênero são reproduzidas e incorporadas na cultura com a naturalização de significados, como os trabalhadores subordinados ligados ao feminino e os líderes ao masculino no século XIX na França (Scott, 1995). Compreender a historicidade admite a possibilidade de mudança nas significações de gênero. Da mesma maneira que novos significados culturais podem levar a sua reinterpretação, eles também podem reafirmar noções antigas de gênero. 
As mães desempenham um importante papel na formação da ideia de beleza, uma vez que são elas quem transmitem os valores culturais de gênero e feminilidade construídos através do corpo (Reischer; Koo, 2004). Scott (1995) aponta que outras instituições como a educação, o sistema político e o mercado de trabalho também exercem influência na construção desses valores, mas, como aprofundaremos adiante, a maternidade tem protagonismo na formação valorativa dos sujeitos pesquisados. No estudo com adolescentes, Nichter (2000) observou diferenças étnicas no ideal de beleza. Enquanto meninas brancas falam sobre ser esbelta e jovens, as negras têm uma visão mais flexível atrelando a beleza a estilo e atitude mais do que ao tamanho do corpo. Tais dados evidenciam as divergências culturais e revelam a especificidade do corpo belo e da forma de atingi-lo.

Retomando o exemplo da obesidade de mulheres da África Central, Reischer e Koo (2004) pretendem desmistificar a magreza como condição quase natural do corpo feminino predominante na cultura ocidental. As diferenças também podem ser históricas, os corpos largos hoje vistos como doença e até pobreza já foram sinônimos de prosperidade, saúde e posição social alta. Nesse sentido, torna-se evidente que a fisionomia do indivíduo passa uma mensagem.

Para autores como Bordo (1993), o padrão de beleza é uma forma de exercer poder e controle social, uma vez que influencia no comportamento diário. Wolf (1991) observou que o crescimento de distúrbios alimentares na década de 1980 coincidiu com o aumento de mulheres em posição de poder e autoridade no trabalho. A autora argumenta que a beleza é usada como forma de controlar o acesso das mulheres ao poder porque ela seria um atributo desejado por elas, é como uma moeda de troca para ter poder. Dessa forma, o sucesso profissional das mulheres estaria atrelado à vigilância e modificações no corpo que mantenham o padrão. No entanto, a dificuldade em manter a aparência de acordo com o ideal revelaria a falta de autocontrole e disciplina.

No que diz respeito ao uso de cirurgias plásticas para modelar o corpo, Gilman (1998) observou que esse recurso é uma forma de terapia psicológica. Isso reflete o poder simbólico do corpo sob o psicológico. No estudo com mulheres de origem asiáticas que fizeram cirurgia para deixar os olhos mais ocidentais, Kaw (1994) descobriu que, apesar de atribuírem a decisão a questões individuais, a escolha dessas pessoas tinha como pano de fundo a visão negativa que os americanos têm do corpo asiático, o que significaria passividade. Novamente observamos como a personalidade é associada ao corpo, este representaria a essência do indivíduo (Reischer; Koo, 2004).

Por outro lado, Orbach (1978) aponta que ser uma mulher gorda em uma sociedade na qual a magreza é o ideal de beleza pode ser uma forma de resistir ao estereótipo de gênero. Se ele é o espaço para prática de controle social e poder, também pode ser objeto de negociação dos valores $e$ significados sociais. A mulher pode lutar para ter a sua própria imagem através da oposição ao padrão imposto. Para superar as limitações simbólicas e as diferenças de gênero que existem no ambiente de trabalho, as mulheres são capazes de moldar seus corpos. Segundo Reisher e Koo (2004:315, tradução nossa),

reconhecendo a natureza altamente codificada da beleza, as mulheres aprenderam a se apropriar do simbolismo do corpo para alcançar seus próprios fins. Os corpos das mulheres e as construções sociais da forma feminina ideal, mais do que refletem a posição das mulheres na sociedade: oferecem um meio poderoso para negociar, redefinir e reconceituar essa posição. No entanto, essas formas de resistência ocorrem dentro de estruturas sociais abrangentes que, em última instância, indexam as relações de poder existentes.

O uso do corpo como protesto também foi abordado por Ellmann (1993). A autora identificou uma semelhança entre mulheres anoréxicas e as que fazem greve de fome, ambas usam seus corpos como discurso. Nesse sentido, "o corpo é central para expressão pessoal e política [...] ele abre um território simbólico poderoso para articulação da dissidência contra formas de opressão social ou política" (Reischer; Koo, 2004:303, tradução nossa). Isso significa que o corpo não é mero reprodutor do sistema simbólico, a sua manipulação tal como uma "massa de modelagem" permite que ele represente uma forma de resistência e transformação dos valores hegemônicos. Um outro 
exemplo dessa resistência são os concursos de beleza. Até recentemente as vencedoras representavam como ideal de beleza uma mulher branca, hoje já há Miss Universo de outras etnias.

$\mathrm{O}$ foco em mulheres se justifica a partir do aspecto da experiência feminina, como abordado anteriormente. Para além disso, o presente estudo traz questionamentos sobre o movimento slowbeautytomando o corpo como um espaço de simbolismo e agenciamento do mundo social, no qual as mulheres imprimem formas que refletem e refutam os valores hegemônicos.

\section{Apresentação do campo}

O levantamento de comunidades virtuais de slow beauty apontou para uma existência massiva de grupos exclusivamente no Facebook com objetivo de trocar ideias sobre cosméticos alternativos sem reconhecer o movimento. Entre as comunidades virtuais que mencionavam o slow beauty estavam a Beleza Minimalista e a Vivo Naturalmente. A escolha pela segunda como objeto do presente trabalho se deu em função de sua presença também no ambiente off-line. Para Hine (2015) a produção de sentido se dá na esfera digital e presencial e, para captá-la, é importante investigar essas duas dimensões. Enquanto comunidade, com mais de 200 membros, a Vivo Naturalmente ${ }^{3}$ reconhece o movimento, faz parte do ambiente digital, possui encontros e relações presenciais e, portanto, é a mais adequada aos nossos objetivos.

Entrevistamos 17 membros $^{4}$ da comunidade e para selecioná-las consideramos os seguintes critérios de inclusão: o sexo feminino, compreendendo a experiência feminina da beleza na qual o corpo traz aspectos da vida social refletindo e refutando valores hegemônicos; a participação no ritual de passagem juntamente com as pesquisadoras, por compreender a importância dessa etapa para a formação da identidade dos membros e pela proximidade com as mesmas; a presença na comunidade desde o início, para trazer uma visão histórica e mais consolidada do movimento; o engajamento na comunidade digital, por compreendê-lo como essencial para a conexão emocional; e possuir perfis no Facebook e Instagram para cruzar com a identidade construída na comunidade. A Tabela 1 traz o perfil e as motivações das entrevistadas.

Tabela 1: Perfil das entrevistadas

\begin{tabular}{|l|l|l|l|}
\hline Nome Fictício & Idade & Profissão & Motivação \\
\hline Coral & 35 & Pesquisadora & Mudança no consumo \\
\hline Cloé & 36 & Produtora & Buscandoumavida natural \\
\hline Lis & 52 & Dona de casa & Autoconhecimento \\
\hline Susana & 27 & Parapsicóloga & Autoconhecimento \\
\hline Débora & 33 & Diretora de escola & Resgate das raízes \\
\hline
\end{tabular}

\footnotetext{
3 Para desvendar o significado das práticas das adeptas ao movimento slow beauty e a construção identitária e da imagem corporal feminina, foi feita uma observação participante das aulas do curso de Introdução à Aromaterapia da comunidade Vivo Naturalmente. Fundada em 2014 por Fernanda Telles e seu marido, Alcir Blondet, inicialmente como uma marca na busca por produtos menos agressivo no cuidado da filha, ela se transformou em comunidade. Atualmente reúne participantes dos cursos de Fernanda em dois grupos no Whatsapp chamados Vivo Naturalmente e Compras Coletivas para compartilhar conhecimento e trocar sobre um estilo de vida mais saudável e cosmética natural.

4 Realizamos entrevistas em profundidade com 17 membros do grupo Vivo Naturalmente. As entrevistadas eram mulheres entre 25 e 55 anos que buscam uma mudança de vida e um autoconhecimento, especialmente motivadas pelo estresse de um modo de vida pautado no sucesso, no poder e no dinheiro. Elas trabalham nas mais diversas áreas: enfermeiras, fotógrafas, biólogas, químicas, nutricionistas, empreendedoras e atrizes, e muitas se identificam como mães. Extremamente engajadas no movimento, participam ativamente da comunidade digital e compartilham em suas redes sociais seus valores, crenças e processo de transformação.

5 Os nomes das entrevistadas foram substituídos por fictícios para preservar suas identidades como é usual na tradição antropológica.

6 Motivação refere-se à entrada no curso.
} 


\begin{tabular}{|l|l|l|l|}
\hline Carina & 31 & Designer & Mudança no consumo \\
\hline Estela & 35 & Professora & Autoconhecimento \\
\hline Naia & 45 & Empreendedora & Conheceraromaterapia \\
\hline Silvia & 42 & Atriz & Maternidade \\
\hline Iolanda & 55 & Nutricionista & Produtosnaturais \\
\hline Luna & 47 & Professora & Mudança no consumo \\
\hline Rosa & 25 & Fotógrafa & Maternidade \\
\hline Deise & 26 & Química & Mudança no consumo \\
\hline Camélia & 28 & Advogada & Mudança de vida \\
\hline Maia & 55 & Nutricionista & Mudança de vida \\
\hline Flora & 29 & Jornalista & Mudança de vida \\
\hline Violeta & 29 & Design de Interiores & Maternidade \\
\hline
\end{tabular}

Dessa forma, a presente pesquisa ${ }^{7}$ investigou o slow beauty através da comunidade Vivo Naturalmente, formada por alunas e ex-alunas dos cursos de Fernanda Telles, uma referência no movimento. Os nomes dos idealizadores da comunidade foram mantidos com autorização dos mesmos - Fernanda Telles e Alcir Blondet. Os das integrantes foram substituídos por nomes fictícios para preservar suas identidades. O trabalho de campo foi realizado em três etapas: observação participante no ritual de passagem; observação participante da comunidade virtual; e entrevistas em profundidade.

\section{Ritual de passagem}

A pesquisa teve início com a observação participante do ritual de passagem no curso de Introdução à Aromaterapia e Alquimia em julho e outubro de 2018. A partir da adoção de uma abordagem da cultura material que valoriza os artefatos, tal como Miller (1998; 2007), Vannini (2009) e Machado (2015a; 2015b) apontam, foram observados também os valores práticos e simbólicos, os usos e significações dos objetos, como os cristais para a purificação. Para investigar a racionalidade e a estrutura social proposta por autores como Mauss (2003 [1950]), Van Gennep (2011 [1909]) e Rodrigues (1979; 1992), foram examinadas as justificativas e finalidades para os usos de produtos e de cada ingrediente, os modos de preparo, o responsável pelo ato, as ferramentas, os materiais, as condições de tempo e lugar, os ritos de entrada e condições do "mágico", como vestimentas e estado de espírito, os ritos orais e de saída.

$\mathrm{O}$ rito de passagem é um momento presencial que marca a entrada de novas integrantes, para tanto, elas precisam passar por um curso de dois dias. No primeiro, elas são recebidas com um ritual preparatório para fornecer um ambiente acolhedor e de cuidado, no qual elas se sintam à vontade para relevar suas motivações, em sua maioria ligadas à frustação diante de um ideal de vida universal com o qual elas não se identificam. Então, aprendem a parte teórica, os mitos, ritos, materiais e prescrições essenciais para fazer parte da comunidade. Já no segundo, "colocam a mão na massa" confeccionando cosméticos com o que estudaram, através de sinergias $e$ experimentações que valorizam o gosto individual que aflora a coletividade através do

\footnotetext{
7 Submetida ao Comitê de Ética do Centro de Filosofia e Ciências Humanos ( $\mathrm{CFCH}$ ) da UFRJ através da Plataforma Brasil e aprovada em 24 de maio de 2018 sob o número 2673843.
} 
compartilhamento. Findando o ritual de passagem, elas passam a fazer parte da comunidade e são incluídas nos grupos do WhatsApp.

A relação com a liderança comunitária e os membros nos permitiu a entrada e participação no grupo tal como as formadas no curso. Percorrer o mesmo caminho das novas integrantes nos trouxe uma perspectiva mais próxima da realidade do ritual de passagem, do aprendizado necessário às boas-vindas no ambiente digital. Em sua proposta de etnografia digital, Hine (2015) evidencia a necessidade de se engajar nas atividades da mesma maneira que os membros da comunidade para compreender como o sentido é produzido, percorrendo a vivência complexa $e$ expressões que as particularidades desse ambiente e dessa trilha fazem emergir. Isso porque a experiência digital não é fixa, ela tem seu significado construído nas relações e conexões que são estabelecidas diariamente. Seu estudo deve, então, abranger como as pessoas se movimentam, evidenciam ou ignoram determinados aspectos enquanto vivem seu cotidiano.

\section{A identidade bruxesca}

Três dias após o curso, fomos adicionadas por Fernanda no grupo Vivo Naturalmente e no grupo Compras Coletivas do aplicativo para celular WhatsApp para observar e levantar questões, de julho de 2018 a fevereiro de 2019. No roteiro que guiou a observação, levantamos questões relativas à interação e à relação entre os membros do grupo e o conteúdo das conversas. A linguagem, a questão da colaboração e construção conjunta do movimento, a utilização das ferramentas digitais e os conflitos da comunidade são aspectos importantes relativos a essas primeiras questões. No que diz respeito à questão da identidade, nos interessou compreender as expressões no corpo típicas desse movimento. Questionamos também o papel dos bens no slowbeauty, bem como os significados das práticas, mitos e ritos compartilhados por essas mulheres. Nesse ponto observamos as justificativas, as finalidades, as condições e as prescrições.

A primeira turma já havia trocado números de celular e criado o próprio grupo que logo se desfez com a migração para os principais. Já a segunda turma manteve seu grupo separado para uso esporádico, o nome Pythonissam foi dado em homenagem às bruxas. Ele remete à sacerdotisa grega Pitonisa e é a versão em latim da palavra bruxa, segundo Iolanda. Débora, aluna da segunda turma, relembra que as mulheres eram oráculos na Grécia antiga, "portais de energia, usavam a natureza para curar". A ideia foi aprovada por todas.

Logo no início da observação da comunidade digital algumas compartilharam seus sentimentos em relação à experiência vivida presencialmente, exaltaram a energia, a conexão e o resgate. Débora evidenciou o sentimento de volta às origens em meio à "energia de transformação, acredito que todas sentimos o poder da Natureza em suas formas mais puras e essenciais". Flora relata ter tido um reencontro com o que já viveu em outras vidas e o que busca para essa conexão, "é possível viver a conexão com nosso sagrado e com a Mãe Terra". Fernanda agradece o refúgio diante dos temores que uma eleição ${ }^{8}$ conturbada com grande polarização proporciona: "será que corremos o risco de não poder mais falar o nome 'bruxa' visto que a fala desse nome é tão antiga em minhas memórias celulares mas também tão temerosa pela palavra calada? $\mathrm{O}$ temor que o patriarcado 9 em suas fogueiras nos provocou" questiona, para então revelar o ambiente acolhedor da comunidade, "agradeço a luz das palavras queridas. Me sinto mais segura com elas, abraçada em irmandade e o elixir de cuidado/energia feminina". Iolanda resume a experiência do ritual de passagem ao passo em que enfatiza o poder da soma das energias das bruxas de hoje em uma egrégora de transformação (Figura 1).

\footnotetext{
8 Para presidente, governadores, senadores e deputados pelo Brasil em 2018.

9 O termo foi amplamente discutido no campo dos estudos feministas para análise das relações de gênero. Morgante e Nader (2014) trazem um debate teórico sobre o conceito e seus usos nos estudos contemporâneos, separando sua aplicação adjetiva com origem weberiana — no patriarcalismo - da substantiva e mais frutífera para análise das relações contemporâneas. Essa, compreende o patriarcado como um sistema de dominação que atua em diferentes esferas tais como família, mídia e política. As autoras enfatizam a necessidade de "situar historicamente patriarcado, considerando as complexas transformações nas relações de gênero da sociedade moderna" (Morgane; Nader, 2014:8).
} 
Figura 1: Mensagem de Iolanda na comunidade Pythonissam

Mulheres lindas $\mathcal{O}$ amei muito nossa experiência neste fds. Foi mágico. Pra mim é muito gratificante encontrar mulheres assim como vcs que estão nesse resgate. Muitas vezes a gente se sente sozinha nessa busca, nesse reencontro com a nossa essência divina. Somos sim bruxas. Sem medo pelo peso que foi colocado nessa palavra. Somos bruxas pois somos capazes de nos conectar umas com as outras, conosco e com a natureza e criar, mas principalmente criar uma egregora de amor, de cura, de transformação e transmutação, não apenas pra nós mesmas mas para o planeta. Feliz de ter vcs no meu caminho.

Tenham todos um excelente semana, repleta de amor e de luz.

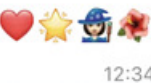

Fonte: Printscreen do grupo no WhatsApp.

Elas seguiram trocando dicas de livros para se aprofundarem no assunto, receitas $e$ procedimentos da cosmética natural. Mais do que isso, essa egrégora proporcionou a construção e a descoberta da subjetividade e da identidade dessas mulheres. Elas resolveram o dilema da crise de identidade através do consumo consciente, essa comunidade estabeleceu fronteiras e produziu sentido a partir das escolhas de consumo, independentemente da aquisição de bens, marcaram a identidade do grupo social no cotidiano, tal como apontam Barbosa e Campbell (2013).

É a exaltação de ser bruxa e mulher que revela a verdadeira identidade das integrantes dessa comunidade. Ser mulher é uma "milenar resistência", unida pelo fio do "sangue-mulher" cuja memória exalta aquelas que já foram. A ancestralidade é um ponto importante para elas, não somente pela retomada dos costumes de preparar os próprios cosméticos, mas pelo saber e luta daquelas que as antecederam. A menstruação é exaltada como símbolo da força feminina, que resiste e guia (Figura 2). Em seu perfil no Instagram, Susana, integrante da segunda turma, postou uma foto com sua mãe exaltando essa milenar resistência com a seguinte legenda "honro a força $e$ a vida que vem de meus ancestrais. Gratidão mãezinha". O resgate da ancestralidade faz parte da construção da identidade, uma vez que elas se reconhecem na projeção dessa mulher de milenar resistência. Fernanda compartilhou uma foto de mulheres nuas de costas em meio à natureza para agradecer a imersão na formação de sacerdotisas, cujo objetivo é o reencontro com a essência feminina. Na legenda, ela explica a experiência:

quando escutei a voz do meu coração e do meu ventre, eu encontrei a mim mesma. Quando honrei meu sangue e minha espiritualidade, encontrei a mim mesma. Quando entreguei minha vida em confiança na egrégora de luz que me guia, encontrei minha linhagem, minhas ancestrais e também encontrei a mim mesma.

Figura 2: Mensagem de ancestralidade e luta publicada na comunidade Pythonissam

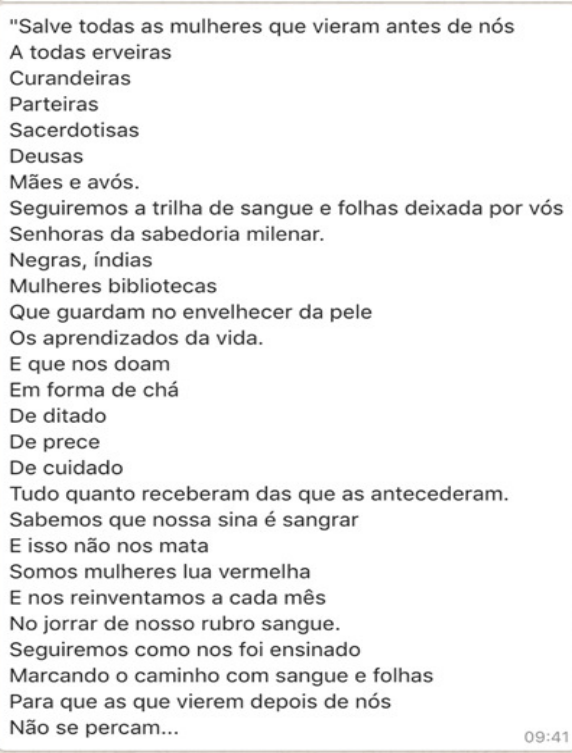

Fonte: Printscreen do grupo no WhatsApp 
Ser bruxa é resistência, mas também é cuidado. Insubordinadas, divergentes, antenadas, sábias, loucas, profundas, espiritualizadas, perigosas, que lutam, que amam, se envolvem, cuidam, com conhecimentos intuitivos, que gestam, nutrem, guiam, bem resolvidas, que servem, que amparam, que estudam, que questionam, que se impõem, que resistem, fantásticas, surreais, feiticeiras, mulheres comuns (Figura 3). A descrição revela a dualidade dessa mulher, que é ao mesmo tempo resistência e manutenção da classificação do papel social de gênero (Gilchrist, 1997). Resistência porque não reproduz a competição feminina, luta contra o machismo, a opressão, estuda, questiona, argumenta e se impõe. Estela, integrante da comunidade desde 2015, explica os motivos pelos quais decidiu seguir a cosmética natural, entre eles, a compreensão de que o fast beauty faz as mulheres "escravas de um único padrão de beleza (mesmo quando fingem que não)". No que diz respeito à competição feminina, Estela aponta como vantagem da cosmética natural conhecer "mulheres maravilhosas" que estão seguindo a mesma trilha e apoiam umas às outras nessa caminhada. Dessa maneira, o slow beautyé também resistência aos valores hegemônicos da beleza feminina. Mas, ao mesmo tempo, permanece aquela imagem da mulher que cuida, que gera filhos. A classificação social do papel da mulher permanece também em relação aos conhecimentos intuitivos, à compaixão e ao fato de serem "guardiães de tudo que é digno e eterno".

Figura 3: Mensagem de resistência e manutenção da ideologia de gênero na comunidade Pythonissam

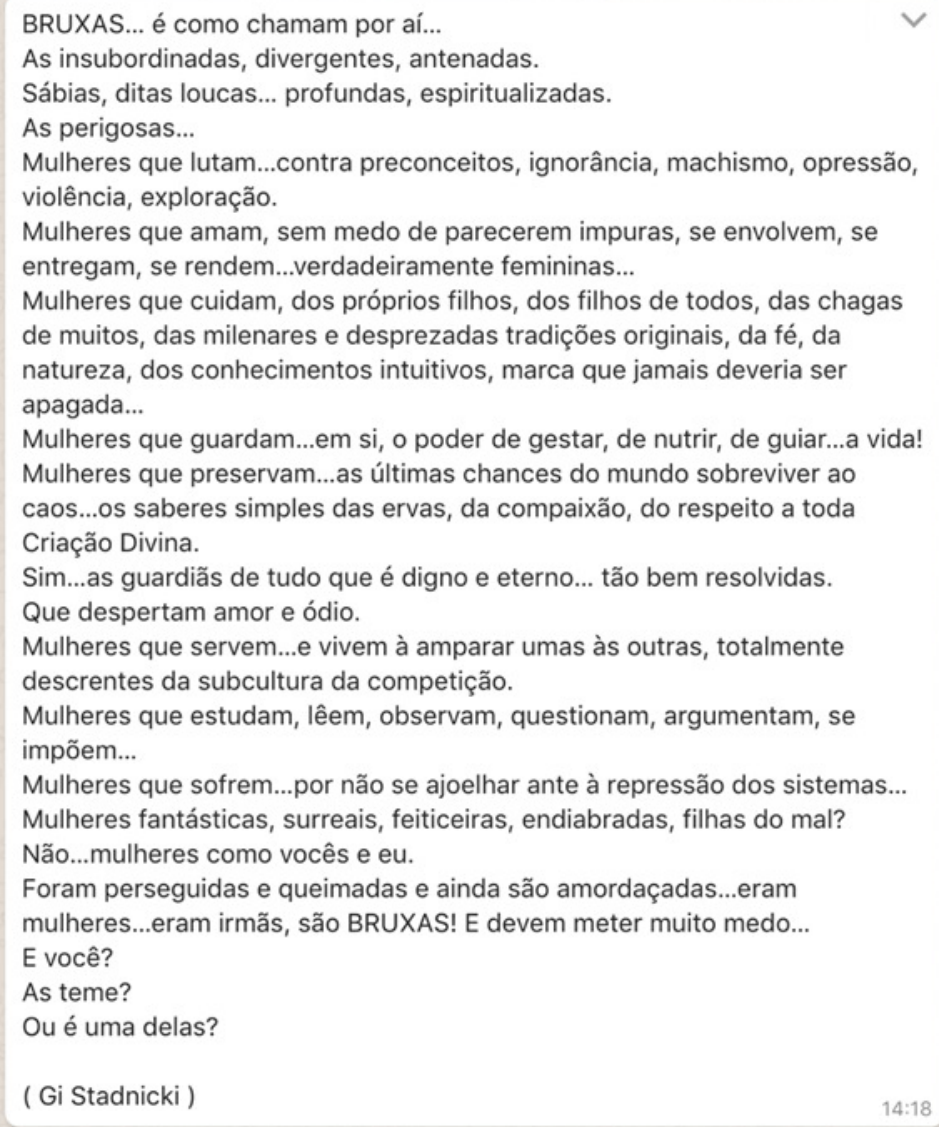

Fonte: Printscreen do grupo no WhatsApp.

A fronteira construída nessa comunidade valoriza o saber da mulher, muitas vezes ligado à ancestralidade, passado geneticamente pelo "sangue-mulher" ou de mãe/avó para filha/neta (Figura 4). Exalta ainda sua capacidade de se transformar ou se adaptar às situações adversas. A intuição feminina, o sexto sentido ou sensibilidade são estereótipos que revelam um lugar na sociedade. Por outro lado, parecem revelar a conexão que as mulheres possuem com a natureza e com a Mãe Terra. Sobre o despertar da mulher sagrada, Fernanda explica em seu Instagram: 
É um chamado profundo para a recuperação da sabedoria ancestral, bem como uma resposta prática às necessidades vitais que temos como mulheres, as quais, geralmente, não são abordados com a responsabilidade e cuidado que merecem. Emerge como um ato revolucionário através do amor, da autoconsciência, do despertar e da descoberta da capacidade de nos autocurar e apoiar a cura de outras mulheres. Temos a filosofia de que todas as mulheres são "mulher medicina" e, juntas, com nossas raízes ancestrais, os nossos dons uterinos são ainda mais fortes.

Figura 4: Mensagem de bruxa sábia e intuitiva na comunidade Pythonissam

A palavra "bruxa" no idioma sânscrito (a língua sagrada da Índia) significa

"mulher sábia". Em latim a palavra bruxa significa larva de borboleta.

Somando os dois significados podemos dizer que ser bruxa é ter a

sabedoria e o poder de se auto transformar. Parabéns a todas as bruxas e a

todas as mulheres que seguem sua intuição, que consideram o seu sexto

sentido, que conseguem transformar as situações ruins em aprendizado e

ainda sair voando!

Feliz dia das Mulheres Sábias!

Fonte: Printscreen do grupo no WhatsApp.

A construção da identidade passa também pela retomada do próprio corpo e da "essência feminina" (Figura 5). Para compreender essa questão é preciso reconhecer o significado simbólico do corpo. Questões socioculturais e históricas influenciam e moldam os sentidos com os quais percebemos e lidamos com o corpo, como indicaram Turner (1994), Douglas (1970) e Mauss (2003). Ao resgatar o debate sobre a armadilha linguística na referência ao corpo, observamos sua menção como propriedade. No entanto, ao contrário do que Becker (1994) encontrou em Fiji, o corpo é fundamental do eu e não do coletivo. Seu cuidado é de responsabilidade individual e não está aberto a críticas coletivas. Mais do que uma referência ao capitalismo, o uso dos pronomes possessivos "seu" ou "meu" indicam uma autonomia e um poder sobre o próprio corpo enquanto luta das mulheres, inclusive contra os valores culturais hegemônicos de gênero e feminilidade transmitidos muitas vezes pelas mães (Reischer; Koo, 2004). Embora possamos compreender que diversos poderes emergem socialmente na formação dos sujeitos, como os gestores do estado, a mídia e a Igreja, nesse estudo, o papel materno ganha protagonismo na construção de valores e legado para as filhas. Isso porque há uma valorização da ancestralidade feminina - seja na resistência ou no aprendizado dos rituais de beleza relatados - e uma representação divina da maternidade com a Mãe Terra ou Mãe Natureza com a qual a comunidade busca se conectar e referenciar. Rodrigues (2014) aponta a demarcação de fronteiras e o recolhimento do corpo para o espaço da casa como uma característica da sociedade contemporânea, em oposição ao corpo coletivo, da rua e dos banhos coletivos da Idade Média. 
Figura 5: Mensagem de retomada do corpo e da essência feminina na comunidade Pythonissam

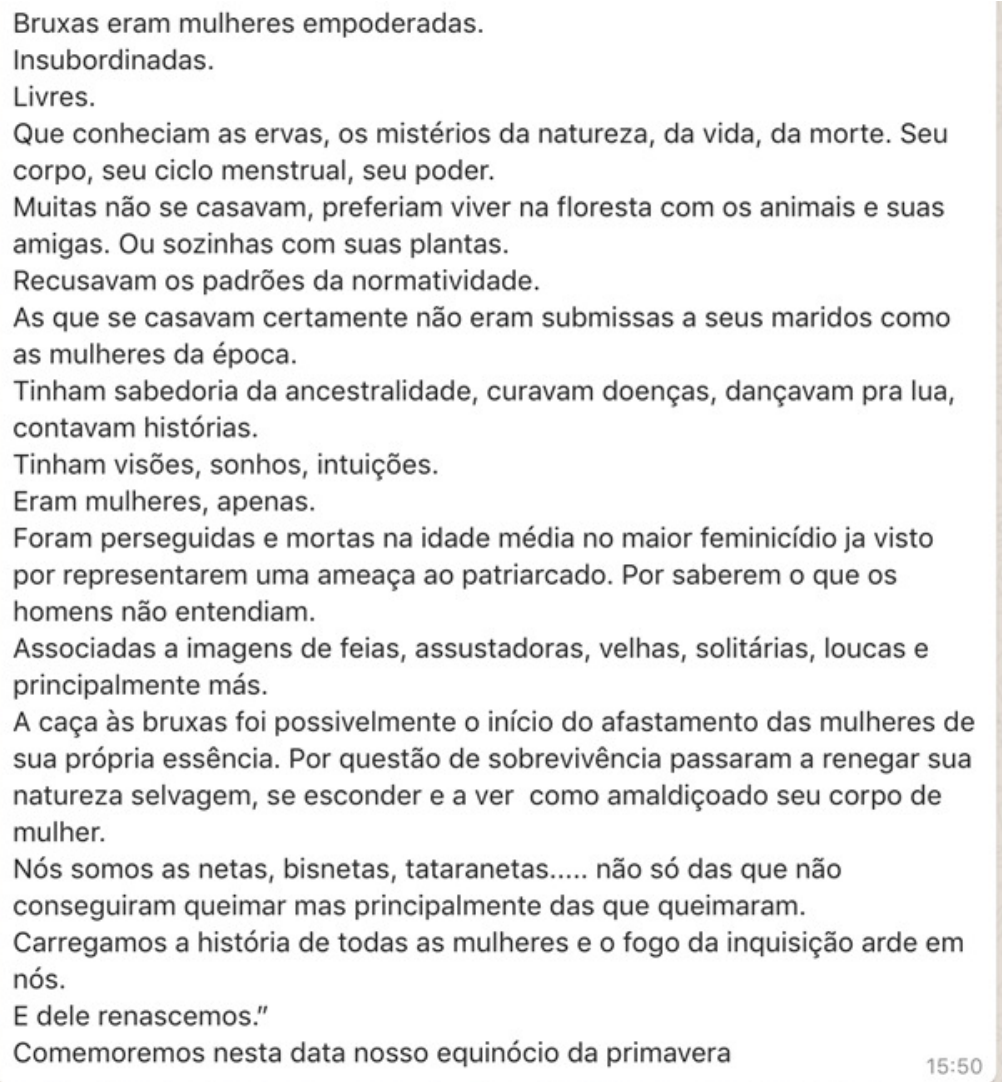

Fonte: Printscreen do grupo no WhatsApp.

Ao analisar historicamente, observamos como o processo civilizador ou de escolarização, apontado por Elias (1994a) e Ariès (1981), naturalizou comportamentos e sentimentos relacionados ao corpo, especialmente os corpos femininos com a "aprendizagem doméstica". Desde cedo as meninas aprendiam a se comportar como adultas com suas mães, a escola era proibida para elas. Ainda que tenham conquistado o direito de estudar, as mulheres continuaram aprendendo com suas mães como "se arrumar para ficar bonita", como relata Estela. Passar xampu, condicionador, sabonete, desodorante, hidratante, pentear os cabelos e passar maquiagem. Hoje, integrante da comunidade, seu ritual de cuidados é completamente diferente, reforçando os caminhos traçados individualmente como composição dos indivíduos (Elias, 1994b). Estela abandonou o condicionador, não utiliza xampu e sabonete em todos os banhos, reduziu o uso de maquiagem $e$ trocou os produtos industrializados por "naturais". Ela explica que a mudança veio com o autoconhecimento, compreendendo suas próprias necessidades, foi adaptando seus hábitos. No entanto, reconhece que é um processo e diz não abrir mão de seu corretivo M.A.C. Em suas redes sociais, ela defende a causa e possui um conjunto de publicações fixas chamado "naturebices", no qual compartilha notícias, explica as vantagens e tira dúvidas de seus seguidores sobre o tema: "aprendi a fazer meus próprios cosméticos e isso me encheu de autoestima e me trouxe muito mais autoconhecimento".

Estela relata que um grande problema foi controlar os odores causados por hormônios que surgiram desde cedo. A questão também foi mencionada em um debate no grupo em setembro de 2018, com uma questão sobre antitranspirante/desodorante para crianças de 8 e 4 anos. Nesse ponto, observamos a mudança apontada por Rodrigues (2014) em relação à sensibilidade contemporânea. O processo de higienização e desodorização chegou ao corpo como asseio ou higiene pessoal, transformando a própria sensibilidade. Os odores que outrora não incomodavam, precisavam agora ser controlados, especialmente a partir da associação da higiene com a saúde.

É interessante observar a presença da visão holística da saúde mencionada durante o ritual de passagem. Para elas, o problema do odor não está apenas ligado à higiene, mas também à 
alimentação. Portanto, a mudança de hábitos dessa comunidade não se restringe ao universo dos cosméticos e produtos de higiene, engloba também a alimentação, a moda e o universo espiritual. Ainda que adotem práticas diferentes, diminuição do uso de sabonete e desodorante, por exemplo, vemos que seus rituais ainda estão ancorados no mito da saúde e da ciência. Reisher e Koo (2004) apontam o uso do discurso biológico e médico da "natureza/essência feminina" como uma forma de amparar a estrutura social, delimitando a atuação a partir do gênero. O que vemos aqui é o contrário, a natureza feminina é o símbolo da reinvenção, a trilha de sangue que marca a luta e a sabedoria daquelas que vieram antes. "Em cada gota que jorra/um fio invisível $e$ tônico/pacientemente cose a rede de nossa milenar resistência", como menciona Iolanda.

Se, por um lado, elas demonstram a sensibilidade contemporânea em relação ao odor $e$ à individualidade do corpo, por outro manifestam a integralidade do universo medieval (Rodrigues, 2014). Em parte, pela retomada da ideia de bruxa, em parte pela busca por uma conexão com a natureza, elas resgataram a espiritualidade e condição humana própria do corpo. Avançaram, no entanto, ao compreender o "corpo de mulher" como valor, como espiritualidade, como esse lugar simbólico e indissociável da constituição do ser. Como na "energia feminina" que Fernanda mencionou na preparação do ritual de passagem, na incapacidade do corpo de lidar com produtos industrializados porque não vêm da natureza, ou na conexão com a Mãe Terra, por exemplo.

Mas afinal, o que é ser bruxa para elas? A questão que perpassa por todas essas características, desde o fazer artesanal de cosméticos, o resgate da ancestralidade ao corpo feminino, é a luta contra a classificação social do papel da mulher. Bruxa "é o retrato da mulher empoderada", diz Iolanda. Ao contrário da princesa que representa o ideal de mulher, ela não precisa de "um príncipe bocó para tirá-la de alguma situação de opressão". Ela é "linda, poderosa e resolve a situação sem ajuda de ninguém". Linda, não porque está de acordo com um padrão estético imposto socialmente, mas por sua força para ser livre. "Sou e serei sempre bruxa

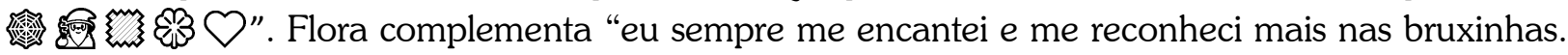
Adoro que me chamem assim!!!! (5)". O mesmo corpo que serve ao controle social e poder, é utilizado como forma de resistência. É também por meio dele que elas negociam os valores $e$ significados sociais, especialmente por meio da oposição ao padrão imposto. No dia 31 de outubro é celebrado o dia das bruxas, a data, de origem pagã, possui um outro significado para essas mulheres. Em suas redes sociais Susana explica:

\begin{abstract}
VIVA LAS BRUJAS! AS MULHERES QUE SE PERMITEM SER! Celebrando 31 de Outubro
Bruxas não são feias, não são corcundas, não têm verruga no nariz, não andam numa vassoura como é estereotipado pelo mundo. São mulheres. Mulheres conectadas com sua essência. Conectadas com a natureza interna e externa. Que respeitam e reconhecem seus limites. Sábias que aceitam suas dualidades, abraçam suas sombras e as transmutam em luz. Sacerdotisas do amor. Curandeiras. Quem resgata a sabedoria ancestral. Quem toma um chá pra passar a dor de cabeça. Quem sente aquele sexto sentido e quando quer descobrir algo é melhor que o FBI. Quem respeita a natureza e a tem como sua aliada. Quem assim como a lua é cíclica. Quem ama. Quem respeita a si e ao outro. Quem não é perfeita, e não se envergonha disso. Quem luta contra o patriarcado, quem exige espaço e luta por ele, quem acredita em magia. Na magia do amor, do bem, da paz, da fé, da oração, da palavra, da força do pensamento, da lei do retorno e da atração, na energia... Quem tem coragem de SER. Livre de amarras e de máscaras. São empoderadas. Livres. Selvagens. Belas. Sensuais. Fortes. Guerreiras. São o que quiserem ser. Têm amor-próprio. São amor, são luz, criatividade, sensibilidade, intuição e poder. São mulheres. E meu bem... Onde há mulher, há magia e se isso é bruxaria, então, somos todas bruxas! Ð क्षे
\end{abstract}

Embora o antagonismo entre bruxa e princesa sirva ao propósito de demarcar o lugar através da oposição e muitas delas se reconheçam do lado de lá, com símbolos que denotam o universo mágico como o chapéu, o caldeirão e a teia de aranha, Carina aponta um caminho mais complexo para a luta: questionar pressupostos. Por que não desconstruir a princesa? O conflito é logo resolvido, "todas as princesas têm um quê de bruxas e fadas". O que une essas mulheres além da luta é a integralidade do universo, isto é, a conexão com a Mãe Natureza. "Somos místicas. Não adianta". "O universo chama", complementa Iolanda. 
A essência feminina e o corpo aparecem aqui como simbolismo e agenciamento do mundo social, refletindo e refutando valores hegemônicos. Observamos a centralidade do corpo feminino na expressão pessoal e política. Ele representa o eu e é através dele, assumindo a "natureza feminina" $e$ as questões biológicas que a cercam, que elas constroem a resistência. Tal como indicam Reicher e Koo (2004), o corpo é um poderoso território simbólico e de dissidência contra opressão para essas mulheres.

\section{Maternidade, uma dimensão da essência feminina}

Como observamos nas etapas anteriores, a maternidade foi o ponto de partida para que muitas das mulheres da comunidade buscassem a transformação. Violeta, por exemplo, procurou a comunidade em um movimento de autonomia no cuidado de seus filhos. Isto é, para que pudesse escolher a melhor forma de cuidar sem utilizar muitos "químicos", e não delegar esse papel aos médicos. Silvia e Rosa também foram em busca de alternativas para o cuidado com seus filhos, como cremes e pomadas menos agressivos. Por outro lado, Lis e Iolanda conheceram o movimento através de suas filhas, que apoiaram suas participações.

Ainda que nem todas sejam mães ou tenham manifestado explicitamente o desejo de ser, a maternidade permeia o discurso das integrantes. Para além daquelas que tiveram os seus filhos como motivação ou mesmo o apoio deles, a maternidade aparece na forma de reconexão com a ancestralidade e com o aprendizado no cuidado diário durante a infância. A figura materna da divindade também tem um importante significado. Cabe ressaltar ainda a associação da maternidade com o cuidado, a sabedoria e a luta que fazem parte da identidade que elas desejam construir.

Para além da motivação, a maternidade faz parte da identidade dessas mulheres. Rosa ressalta: "hoje eu me apresento como mãe". Em sua biografia no Instagram, Estela exalta essa dimensão de sua identidade: "maternagem consciente e sustentável, pesquisadora de modos e modas, professora e palestrante, viajante e criadora". Grande parte de suas publicações são sobre sua filha e a maternidade. O resgate da ancestralidade, a reconexão com o corpo feminino, a essência da mulher e a luta por liberdade também são impulsionados por esse componente fundamental que é ser mãe. Elas marcam "o caminho com sangue e folha" e são "mulheres que guardam...em si, o poder de gestar, de nutrir, de guiar...a vida!". Não por acaso, aquela que provê a vida e a energia é chamada de mãe, Mãe Natureza ou Mãe Terra, com quem elas buscam se conectar e dela usufruem para o cuidado.

Reflexo da motivação e da identidade materna, as menções predominantes estão associadas às palavras filho ou filha. As integrantes da comunidade falam sobre seus filhos e suas preocupações, como já vimos no ritual de passagem. Mas será que essas mensagens são só sobre as aflições da maternidade? Não, ao contrário dos eventos presenciais nos quais observamos o compartilhamento da experiência do cuidado dos filhos, seja nas dificuldades, ou nas alegrias das conquistas dos filhos noticiadas na feira de domingo, a conversa sobre eles na comunidade digital gira em torno de receitinhas "naturais" para resolver problemas pontuais. Durante o inverno, por exemplo, a discussão sobre como tratar rinite, dor de garganta e congestão nasal mobilizou o grupo para pensar alternativas a remédios alopáticos.

O termo mãe e suas variações também foram predominantes nos discursos observados, muitas vezes para se referir à Mãe Natureza ou Mãe Terra. Novamente observamos essa figura materna responsável pela terra, pelo feminino, pela energia que deve ser preservada $e$ reverenciada: "alguém que quer se tratar com a medicina natural, muito antes de se achar no direito de ingerir uma planta que a Mãe Terra generosamente nos presenteia, tem obrigação de honrá-la. Honrar à terra, servir à Pachamama". Essa entidade é também mencionada quando o assunto é autocuidado, para quem busca se reconectar ou encontrar a paz: "parar um pouco e sintonizar com a energia da Mãe Natureza através dos óleos". Além de divindade e de protetora, a Mãe Terra/Natureza aparece como o lugar em que as pessoas vivem. Esse deve ser preservado em busca de harmonia: "gente acho uma coisa super válida, recolher esses óleos que o povo joga fora pra reciclar e assim não contaminar a Mãe Natureza"; "só tento ser parceira da Mãe Terra - do universo pra ter dias. Melhores!!”. 
Quando se fala em maternidade na comunidade, aparecem também as receitas, cuidados e práticas que muitas viveram na infância. As mães possuem a "sabedoria da ancestralidade, curavam doenças, dançavam pra lua, contavam histórias". Se, por um lado, elas aprenderam muitos dos rituais de beleza com suas mães, foi também com elas que aprenderam a ser "bruxas".

Por fim, a figura materna aparece como aquela que cuida por meio de associações. Acácia pede indicação de um óleo para um momento de perda e em que é preciso se manter firme: "sinto que agora minha energia está muito baixa", explica. Cristal indica o óleo de Cipreste e, para explicar resumidamente seu efeito, diz ser "um óleo tipo mãe". Chamado de óleo da transformação, sua associação com a mãe e o cuidado feminino está no fato de trazer "aceitação, apaziguando conflitos e desfazendo culpas internas, eliminando mágoas e tristezas antigas". Observamos também o uso do feminino para designar zelo na descrição de Fernanda do ritual de entrada e na explicação de Flora para a escolha do óleo de Artemísia.

A relação de mãe e mulher com cuidado apareceu também no evocar da identidade "bruxesca" como uma marca que deve ser lembrada: "mulheres que cuidam dos próprios filhos, dos filhos de todos, das chagas de muitos, das milenares e desprezadas tradições originais, da fé, da natureza, dos conhecimentos intuitivos, marca que jamais deveria ser apagada...". Destaca-se ainda a ancestralidade no zelo, que deve ser passado de mães/avós para filhas/netas: "e que nos doam/ em forma de chá/ de ditado/ de prece/ de cuidado/ tudo quanto receberam das que as antecederam".

Observamos o quanto a comunidade no ambiente digital cumpre uma função fundamental na conexão e desenvolvimento da identidade dessas mulheres, como aponta Hine (2015). É por meio dessa plataforma que compõe a vida social, que elas estabelecem relações e fortalecem o sentido de maternidade como expressão de si. Ser mãe faz parte da identidade dessas mulheres, que produzem sentido por meio da troca de conhecimento sobre cuidado com os filhos. Mas elas também aprendem com eles. A maternidade está ligada também ao novo olhar com o qual compreendem a essência feminina, como vimos na seção anterior. Ela remete ao cuidado, à vida, à sabedoria, à luta e à divindade com a qual buscam se conectar.

\section{Considerações finais}

Iniciamos o estudo com reflexões teórico-metodológicas acerca do corpo e da beleza. As discussões a partir do olhar antropológico buscaram fundamentar a visão necessária a um estudo do slow beauty enquanto movimento autêntico de consumo consciente de cosmético, que produz sentido para seus membros e demarca um lugar no mundo. A abordagem da antropologia digital nos permitiu percorrer o mesmo caminho das integrantes, fazendo deste relato o mais próximo possível da realidade. Reconhecemos, no entanto, nossa posição enquanto pesquisadoras, as experiências prévias e as relações estabelecidas a partir da pesquisa como determinantes para a descrição que apresentamos. Dessa forma, compreendemos que outras pesquisas realizadas com o mesmo grupo podem trazer resultados diferentes. Outro fator que contribui para essas múltiplas experiências são as diversas formas de engajamento no campo, especialmente o digital, apontadas por Hine (2015). Dado esse cenário, apresentaremos a seguir as considerações finais que esse percurso nos levou.

Para compreender como o slow beauty impacta na identidade de suas integrantes, foi essencial percorrer o mesmo caminho delas, que chegam ao curso - ritual de passagem insatisfeitas com um modo de vida cujo sucesso é baseado no poder e no dinheiro. Elas buscam mudança de vida, autoconhecimento e o que lhes dá prazer individualmente. A comunidade pesquisada proporciona um movimento de transformação ao estimular a liberdade feminina, reencontro com a essência, a retomada do corpo, a produção criativa e o estabelecimento de novos laços. Dessa forma, o slow beauty vai ao encontro das expectativas iniciais de suas integrantes, preencher essa frustração de uma vida baseada em falsos padrões de avaliação.

Foi através da observação das escolhas para criação dos cosméticos que verificamos uma dualidade crucial para essa comunidade. Enquanto as práticas indicam a busca pela autonomia, emancipação feminina e autodescoberta, certas escolhas e justificativas reforçam o papel social da mulher hegemônico. Alinhavamos, portanto, o conceito de identidade "bruxesca" compreendendo- 
o como um campo de negociações discursivas de nossas interlocutoras sobre o tema da essência feminina.

O conceito de essência feminina é revisto e reatualizado na cultura de nossas interlocutoras. Como Scott (1995) destaca, novas significações de gênero são possíveis, seja reafirmando noções antigas ou reinterpretando, como no caso do presente estudo. Para as integrantes da comunidade, a noção de essência feminina é ressignificada e está ligada à ancestralidade. É a reconexão com a luta daquelas que as antecederam e a conexão com essas mulheres por meio da resistência. Também fazem parte da identidade feminina a intuição e o cuidado. A noção de bruxa reúne todos esses valores e significados, isto é, ela é representação que produz sentido a partir das narrativas construídas (Hall, 2016). Em uma perspectiva, ela representa a luta contra os padrões hegemônicos $e$ a liberdade feminina. Em contrapartida, reproduz o estereótipo da mulher com o sexto sentido $e$ responsável pelo cuidado e geração de vidas. Embora soe contraditório, essas características revelam o poder feminino, especialmente se considerarmos que tais traços são provenientes da conexão e proximidade das mulheres com a Mãe Terra, divindade responsável pela vida e pelo equilibrio.

Nesse contexto, observamos o uso do corpo com o pronome possessivo para indicar sua retomada pelas mulheres. No que tange a inquietação inicial de como o slow beauty transforma a relação das integrantes com o corpo, percebemos que ao retomá-lo, elas o utilizam como forma de resistência para negociar valores e significados sociais e também para reafirmá-los. Ele assume papel central na expressão pessoal e política dessas mulheres e é justamente pela oposição à normatividade que elas negociam os valores e significados sociais. Não querem ser princesas, querem ser bruxas. Elas agora possuem autonomia no cuidado, o que lhes permite adotar práticas e rituais ancorados na visão holística de saúde e beleza. Ao contrário do que indicam Reisher e Koo (2004), o discurso médico da "natureza/essência feminina" é utilizado para reinventar a atuação dessas mulheres, trazendo novas possibilidades de luta e valorizando sua sabedoria, não aparando a estrutura social dominante.

A noção de maternidade também aparece no estudo como um dispositivo importante no reordenamento da noção de essência feminina, especialmente na fala de algumas interlocutoras. De acordo com elas, a maternidade impulsiona os demais elementos como a reconexão, a ancestralidade e a liberdade. Nos debates dos grupos de discussão no WhatsApp, a vivência da maternidade está presente em grande parte da conversa, assim como no contato presencial e diz respeito tanto ao compartilhamento da experiência da maternidade, quanto da reconexão ancestral com as receitinhas de mães e avós. Com elas as integrantes da Vivo Naturalmente aprenderam não só os rituais de beleza padrão, mas a serem bruxas e a se reconectarem com a sabedoria ancestral de resistência. Para elas mãe remete ao cuidado, à vida, à sabedora e à luta. Por fim, a maternidade é representada por uma divindade, a Mãe Terra ou Mãe Natureza. Essa entidade protetora com a qual elas buscam se conectar e referenciar parece fornecer os elementos fundamentais para o cuidado.

\section{Referências bibliográficas}

APPADURAI, Arjun. A Vida Social das Coisas: as mercadorias sob uma perspectiva cultural. Niterói-RJ, EdUFF, 2009.

ARIÈS, Philippe. História Social da Criança e da Família. 2 ed. Rio de Janeiro-RJ, LTC, 1981.

BALSAMO, Anne. Technologies of the Gendered Body: Reading Cyborg Women. Durham, NC, Duke Univ. Press, 1996.

BANNER, Lois. American Beauty. New York, Knopf, 1983.

BARBOSA, Lívia. Sociedade de consumo. Rio de Janeiro-RJ, Jorge Zahar, 2004.

BARBOSA, Lívia; CAMPBELL, Colin. Cultura, consumo e identidade. Rio de Janeiro-RJ, FGV, 2013.

BEAUVOIR, Simone de. O segundo sexo. Nova Fronteira, 2014.

BECKER, Anne E. Nurturing and negligence: working on others' bodies in Fiji. In: CSORDAS, Tommas (ed.). Embodiment and experience: The existential ground of culture and self, v. 2, 1994, pp.100-115. 
BOOKCHIN, Murray. Ecologia social e outros ensaios. Rio de Janeiro-RJ, Achiamé, 2010.

BORDO, Susan. Unbearable Weight: Feminism, Western Culture, and the Body. Berkeley, Univ. Calif. Press, 1993.

BUTLER, Judith. Regulações de gênero. cadernos pagu (42), Campinas-SP, Núcleo de Estudos de GêneroPagu/Unicamp, 2014, pp.249-274.

BUTLER, Judith. Problemas de gênero. Feminismo e subversão de identidade. Rio de Janeiro, Civilização Brasileira, 2010.Tradução de Renato Aguiar.

CANCLINI, Nestor. O consumo serve para pensar. Rio de Janeiro-RJ, edUFRJ, 1995.

CLARK, Jessica. P. Buying Beauty: Female Beauty Consumption in the Modern British World. History Compass, v. 14, n. 5, 2016, pp.206-217.

CONNELL, Raewyn. Masculinities. Berkeley, Univ. Calif. Press, 1995.

DOUGLAS, Mary. Natural symbols: Explorations in cosmology. New York, Pantheon Books, 1970.

DOUGLAS, Mary; ISHERWOOD, Baron. O mundo dos bens: para uma antropologia do consumo. Rio de Janeiro-RJ, UFRJ, 2013.

ELIAS, Norbert. O Processo Civilizador: uma história dos costumes, vol. 1. Rio de Janeiro-RJ, Jorge Zahar Ed, 1994a.

ELIAS, Norbert. A sociedade dos indivíduos. Rio de Janeiro-RJ, Jorge Zahar Ed, 1994b.

ELLMANN, Maud. The Hunger Artists: Starving, Writing, and Imprisonment. Cambridge- MA, Harvard Univ. Press, 1993.

EUROMONITOR. Beauty and Personal Care in Brazil 2016. Brasil, 2016 [http://www.euromonitor.com/beauty-and-personal-care-in-brazil/report - acesso em: 29 jul. 2017].

FALUDI, Susan. Stiffed: The Betrayal of the American Man. New York, Morrow, 1999.

GILCHRIST, Roberta. Gender and material culture: the archaeology of religious women. Psychology Press, 1997.

GILMAN, Sander. Creating Beauty To Cure the Soul. Durham, Duke Univ. Press, 1998.

HALL, Stuart. Cultura e representação. PUC-Rio, 2016.

HINE, Christine. Ethnography for the internet: embedded, embodied and every day. Bloomsbury Publishing, 2015.

HORST, Heather; MILLER, Daniel (ed.). Digital anthropology. A\&C Black, 2012.

ISHIDA, Kaori. From the age of fast beauty to age of slow beauty, the post modern value. International Journal of Cosmetic Science, v. 28, n. 6, 2006, pp.461-461.

KAW, Eugenia. Opening faces: the politics of cosmetic surgery and Asian American women. Manymirrors: Bodyimageand social relations, 1994, pp.241-265.

MACHADO, Monica. Webcam no contexto da antropologia digital. Comunicação, Mídia e Consumo (Online), v. 12, 2015a, pp.146.

MACHADO, Monica. Polymedia e culturas juvenis: estudo de caso em uma favela carioca. Revista $Z$ Cultural (UFRJ), v. Ano X, 2015b, pp.50-65.

MACHADO, Monica. Consumo e politização: discursos publicitários e novos engajamentos juvenis. Rio de Janeiro-RJ, Mauad Editora Ltda, 2011.

MAUSS, Marcel. Sociologia e antropologia. Cosac \&Naify, 2003.

MILLER, Daniel (ed.). Material cultures: Why some things matter. Chicago, University of Chicago Press, 1998.

MILLER, Daniel. et al. How the world changed social media. Londres, UCL press, 2016.

MORGANTE, Mirela Marin; NADER, Maria Beatriz. O patriarcado nos estudos feministas: um debate teórico. Anais do XVI Encontro Regional de História da ANPUH, 2014. 
NICHTER, Mimi. Fat Talk: What Girls and Their Parents Say About Dieting. Cambridge-MA, Harvard Univ. Press, 2000.

ORBACH, Susie. Fat is a Feminist Issue. New York, Paddington Press, 1978.

OSSMAN, Susan. Three Faces of Beauty: Casablanca, Paris, Cairo. Duke University Press, 2002.

PEISS, Kathy. Hope in a jar: The making of America's beauty culture. Pansilvânia, Universityof Pennsylvania Press, 2011.

REDE WWF. Planeta Vivo Relatório $2014 . \quad$ Brasil, 2014. [http://www.wwf.org.br/natureza_brasileira/especiais/relatorio_planeta_vivo/ - acesso em: 12 dez. 2015].

REISCHER, Erica; KOO, Kathryn. The body beautiful: Symbolism and agency in the social world. Annu. Rev. Anthropol., v. 33, 2004, pp.297-317.

RODRIGUES, Jose Carlos. O corpo na história. Rio de Janeiro-RJ, Editora Fiocruz, 2014.

RODRIGUES, Jose Carlos. Ensaios em Antropologia do Poder, Rio de Janeiro-RJ, Terra Nova Editora, 1992.

RODRIGUES, Jose Carlos. Tabu do Corpo. Rio de Janeiro-RJ, Achiamé, 1979.

SCANLON, Jennifer (ed.). The gender and consumer culture reader. New York, NYU Press, 2000.

SCOTT, Joan. Gênero: uma categoria útil de análise histórica. Educação \& realidade, v. 20, n. 2, 1995, pp.71-99.

SILVA, Keliny; COVALESKI, Rogério. A Representatividade do Corpo na Publicidade Brasileira: estereótipos de beleza e o corpo diferente. In: HOFF, T. (org.). Corpos Discursivos: dos regimes de visibilidade às biossociabilidades do consumo. Recife, Editora UFPE, 2016, pp.53-70.

STUART, Avelie; DONAGHUE, Ngaire. Choosing to conform: The discursive complexities of choice in relation feminine beauty practices. Feminism \& Psychology, v. 22, n. 1, 2012, pp.98-121.

TURNER, Terence. Bodies and anti-bodies: flesh and fetish in contemporary social theory. In: CSORDAS, Thomas (ed.). Embodiment and experience: The existential ground of culture and self, v. 2, 1994, pp.2747.

VAN GENNEP, Arnold. Os ritos de passagem. 2. ed., Petrópolis-RJ, Vozes, 2011 [1909].

VANNINI, Phillip (ed.). Material culture and technology in everyday life: Ethnographic approaches. Peter Lang, 2009.

WOLF, Naomi. The Beauty Myth. New York, Morrow, 1991. 